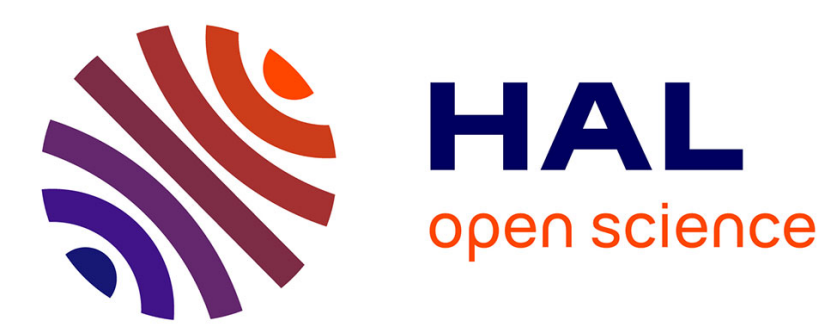

\title{
Is the coefficient of variation a valid measure for variability of stable isotope abundances in biological materials?
}

Oliver Brendel

\section{- To cite this version:}

Oliver Brendel. Is the coefficient of variation a valid measure for variability of stable isotope abundances in biological materials?. Rapid Communications in Mass Spectrometry, 2014, 28 (4), pp.370376. 10.1002/rcm.6791 . hal-01268540

\section{HAL Id: hal-01268540 \\ https://hal.science/hal-01268540}

Submitted on 28 May 2020

HAL is a multi-disciplinary open access archive for the deposit and dissemination of scientific research documents, whether they are published or not. The documents may come from teaching and research institutions in France or abroad, or from public or private research centers.
L'archive ouverte pluridisciplinaire HAL, est destinée au dépôt et à la diffusion de documents scientifiques de niveau recherche, publiés ou non, émanant des établissements d'enseignement et de recherche français ou étrangers, des laboratoires publics ou privés. 
This is the peer reviewed version of the following article: Brendel, O. Is the coefficient of variation a valid measure for variability of stable isotope abundances in biological materials?, Rapid Commun. Mass Spectrom, 2014, 4, 370-376, which has been published in final form at DOI: 10.1002/rcm.6791. This article may be used for non-commercial purposes in accordance with Wiley Terms and Conditions for Self-Archiving.

\title{
Is the coefficient of variation a valid measure for variability of stable isotope abundances in biological materials?
}

Author : Oliver Brendel ${ }^{1,2}$

\section{Address :}

${ }^{1}$ INRA, UMR1137 “Ecologie et Ecophysiologie Forestières”, F-54280 CHAMPENOUX, France

${ }^{2}$ Université de Lorraine, UMR1137 “Ecologie et Ecophysiologie Forestières”, Faculté des Sciences, F-54500 VANDOEUVRE-LES-NANCY, France

\section{Email :}

oliver.brendel@inra.fr

\begin{abstract}
Rationale : Isotopic compositions of low-mass elements such as carbon are commonly expressed on the $\delta$ scale, relative to the isotopic ratio of an international standard $\left(\mathrm{R}_{\mathrm{ST}}\right)$. Carbon stable isotope measurements of plant material are interpreted with an apparently biological meaning as an estimator of water use efficiency, which has been used widely in recent years to screen plant material for variation. To compare the observed variability with other traits, the coefficient of variation $(\mathrm{CV})$ is often used as an intrinsic variability measure.

Methods : Theoretical considerations as well as an example data-set were used to test the independence of the $\mathrm{CV}$ from the $\mathrm{R}_{\mathrm{ST}}$ on which values of isotopic composition on the delta scale are based.

Results : It can be shown mathematically that the $\mathrm{CV}$ of a data-set of $\delta^{13} \mathrm{C}$ values is directly dependent on the $\mathrm{R}_{\mathrm{ST}}$. The exploration of the example data-set confirmed this but also showed that the conversion of absolute isotopic ratios into atom fraction does not change the resulting $\mathrm{CV}$. Similarly, a discrimination calculated between two $\delta^{13} \mathrm{C}$ is independent from $\mathrm{R}_{\mathrm{ST}}$, but depends on accurate knowledge of both $\delta^{13} \mathrm{C}$ values. It was also shown that results of statistics (e.g. ANOVA) are robust among different units of isotopic composition.

Conclusions : As CVs estimated from isotopic compositions expressed on the $\delta$ scale depend on the underlying standard, they should not be compared to those of other traits, and even comparisons of CVs among isotopic data-sets should be interpreted with care.
\end{abstract}

Overall 245 words

\section{INTRODUCTION}


The determination of stable isotope abundances of low-mass elements such as hydrogen, carbon, nitrogen and oxygen using an Isotope Ratio Mass Spectrometer (IRMS) is done by measuring the ratio between the heavy versus the light isotope of a given gas, e.g. for carbon this would be the ratio of ${ }^{13} \mathrm{CO}_{2} /{ }^{12} \mathrm{CO}_{2}$. However, after a formalism introduced by Urey ${ }^{[1][2]}$, stable isotope compositions are commonly expressed on the delta " $\delta$ " scale, which calculates the isotopic ratio of the sample relative to a commonly accepted standard. For carbon, this would be:

$\delta \mathrm{C}=\left(\frac{R}{R_{\mathrm{ST}}}-1\right)$ Equation 1

where $\mathrm{R}$ and $\mathrm{R}_{\mathrm{ST}}$ are the ${ }^{13} \mathrm{C} /{ }^{12} \mathrm{C}$ isotope-number ratios in the sample and reference $\mathrm{CO}_{2}$, respectively.. The relative $\delta$ scale, rather than the absolute ratios $\mathrm{R}$, is used because equilibrium or kinetic characteristics between isotope species of one element differ only by a few percent, resulting in small fractionations ${ }^{[3]}$. Therefore, highly precise measurements are required, which need to be controlled for long term stability by using an international standard.

A positive value in the $\delta$ notation means that the isotopic ratio of the sample is higher (i.e. contains more of the heavier isotope) than that of the standard and inversely for a negative $\delta$ value. International reference materials have been introduced very early for each element ${ }^{[2]}$. . For carbon, the initially accepted reference material was obtained from a Cretaceous fossil (Belemnite) from the Pee Dee formation in South Carolina ("PDB"). This has been recently replaced by the Vienna PDB "VPDB" scale, which is defined by assigning the value of $+1.95 \%$ with respect to $\mathrm{PDB}^{[4]}$. A more detailed discussion on standardisations of isotope measurements and its units can be found in ${ }^{[5]}$. An alternative scale to express isotopic composition is atom fraction $(A F)^{[6]}$, often used in tracer experiments using molecules enriched in the heavy isotope. Atom fraction is defined as the ratio between heavy versus all stable isotopes, e.g. for carbon stable isotopes:

$\mathrm{AFC}=\frac{[C]}{[C]+[C]} \quad$ Equation 2

To avoid systematic errors in mass balance equations, Corso and Brenna ${ }^{[7]}$ introduced the relative isotope fraction $\Phi$, defined as:

$\Phi^{13} \mathrm{C}=\left[1-\frac{\mathrm{AFC}}{\mathrm{AFC} C_{\mathrm{ST}}}\right]$ Equation 3

Often isotopic compositions are used to calculate isotopic discrimination between a source and a product molecule. This is especially the case in plant sciences, where the measurement of $\delta^{13} \mathrm{C}$ has found an increasing importance as an estimator of water use efficiency (WUE), the ratio of accumulated carbon to water lost. To be more precise, the isotopic discrimination $(\Delta)$ between the isotopic composition of atmospheric $\mathrm{CO}_{2}$ surrounding a plant $\left(\delta^{13} \mathrm{C}_{\mathrm{atm}}\right)$ and plant assimilated carbon $\left(\delta^{13} \mathrm{C}_{\text {plant }}\right)$ has been related in a theoretical model by Farquhar and Richards ${ }^{[8]}$ to the ratio of net $\mathrm{CO}_{2}$ assimilation rate to stomatal conductance for water vapour, the intrinsic water use efficiency $\left(\mathrm{W}_{\mathrm{i}}\right)$. Thus when atmospheric $\mathrm{CO}_{2}$ is fixed by a plant during carbon assimilation, the associated discrimination is calculated as:

$\Delta=\frac{\delta^{13} C_{\text {atm }}-\delta^{13} C_{\text {plant }}}{1+\delta^{13} C_{\text {plant }}}$ Equation 4

The measurement of $\delta^{13} \mathrm{C}$ of plant organic material has found an increasing popularity, notably in plant breeding and functional ecology, as a tool to screen large populations of plants for variation or diversity in $\mathrm{W}_{\mathrm{i}}^{[9-11]}$, as direct measurements of WUE are difficult and time consuming. This has especially been the case in recent years, as genotyping has become cheaper and the populations screened for genetic diversity have become larger. 
In many such studies, diversity of different target or functional traits are compared among treatments, harvests, genotypes, varieties, species etc. When comparing the variation of traits that differ appreciably in their means or their measurement units, or to compare relative amounts of variation in populations having different means ${ }^{[12]}$, the coefficient of variation $(\mathrm{CV})$ is often used as an intrinsic variability measure ${ }^{[13]}$. The $\mathrm{CV}$ is defined (Equation 5 ) as the absolute value of the standard deviation $(\sigma)$ expressed as a percentage of the mean $(\mu)$. Therefore the CV does not depend on the units in which the data were measured and thus is dimensionless:

$\mathrm{CV}=\frac{\sigma}{\mu} \quad$ Equation 5

The CV is also used in population genetics: Houle ${ }^{[14]}$ suggested that the "additive genetic CV", which is the ratio between a standard deviation estimated from genetic variance and the population mean, represents an estimate of the relative evolvability of fitness. The CV has therefore been used in studies concerning functional or evolutionary ecology to compare a) phenotypic diversity of $\delta^{13} \mathrm{C}$ ${ }^{[15],[16]}$ or of carbon isotopic discrimination $\Delta^{[17],[18]}$ and b) evolvability using the genetic $\mathrm{CV}$ of $\delta^{13} \mathrm{C}$ [19], [20] or of $\Delta^{[21],[22]}$ with that of other traits.

However, already Zar ${ }^{[23]}$ suggested that the $\mathrm{CV}$ has relevance only for data where an observation equal to zero represents the absence of the measured characteristic, whereas the delta scale includes "zero" as a meaningful value, meaning a sample that has the same isotopic composition as the standard. Also Lauteri ${ }^{[21]}$ suggested that the comparison of the $\mathrm{CV}$ of isotopic discrimination with other traits might not be straight forward and Brendel ${ }^{[24]}$ pointed to a possible problem of interpretation of the $\mathrm{CV}$ relating to the use of a standard.

The present study therefore asks the following questions:

- Is the transformation from $\mathrm{R}$ (the isotopic ratio) scale to the $\delta$ scale robust in terms of estimations of variations?

- More generally, is the $\delta$ scale robust for statistical tests (e.g. ANOVA, variance components)?

- How does the expression of isotopic abundance on different scales (atom fraction, relative isotope fraction or discrimination $\Delta$ ) affect the estimation of variation?

The questions will be elucidated by means of theoretical considerations and an example data set.

\section{THEORETICAL CONSIDERATIONS}

The mean $(\mu)$ is defined as the sum of the items divided by the sample size (n), here given for the isotopic composition $\delta \mathrm{X}$, where $\mathrm{X}$ replaces the element symbol :

$\mu_{\delta}=\frac{1}{n} \sum \delta \mathrm{X}_{i}$ Equation 6

and the standard deviation is given as follows :

$\sigma_{\delta}=\sqrt{\frac{\sum\left(\delta \mathrm{X}_{i}-\overline{\delta \mathrm{X}}\right)^{2}}{n-1}}$ Equation 7.

The delta notation in Equations 6 and 7 can be replaced by Equation 1 : 
$\mu_{\delta}=\frac{1}{n} \sum\left(\frac{R_{i}}{R_{\mathrm{ST}}}-1\right)=\frac{1}{R_{\mathrm{ST}}} \mu_{R}-1 \quad$ Equation 8

$\sigma_{\delta}=\sqrt{\frac{\sum\left(\delta_{i}-\mu_{\delta}\right)^{2}}{n-1}}=\sqrt{\frac{\sum\left(\left(\frac{R_{i}}{R_{\mathrm{ST}}}-1\right)-\left(\frac{1}{n} \sum\left(\frac{R_{j}}{R_{\mathrm{ST}}}-1\right)\right)\right)^{2}}{n-1}}=\frac{1}{R_{\mathrm{ST}}} \sqrt{\frac{\sum\left(R_{i}-\frac{1}{n} \sum R_{j}\right)^{2}}{n-1}}=\frac{1}{R_{\mathrm{ST}}} \sigma_{R} 9$

Equations 8 and 9 can then be used to estimated the coefficient of variation based on the isotopic ratio $\mathrm{R}$ :

$\mathrm{CV}_{\delta}=\frac{\sigma_{\delta}}{\mu_{\delta}}=\frac{\frac{1}{R_{\mathrm{ST}}} \sigma_{R}}{\left(\frac{1}{R_{\mathrm{ST}}} \mu_{R}\right)-1}=\frac{\sigma_{R}}{\mu_{R}-R_{\mathrm{ST}}} \quad$ Equation 10

It can easily be shown that this demonstration is similar for the $\Phi$ notation, using equation 3 :

$\mathrm{CV}_{\Phi}=\frac{\sigma_{R}}{\mu_{R}-\mathrm{AF} C_{\mathrm{ST}}}=\frac{\sigma_{R}}{\mu_{R}-\frac{R_{\mathrm{ST}}}{1+\mathrm{R}_{\mathrm{ST}}}}$

This shows clearly that the CV calculated from values using the $\delta$ or the $\Phi$ scale are dependent on the isotopic ratio of the standard used. Equation 10 was used to plot the theoretical, hyperbolic relationship between $\mathrm{R}_{\mathrm{ST}}$ and CV (Figure 1).

Concerning the calculation of isotopic discrimination between atmospheric $\mathrm{CO}_{2}$ and plant material, using Equations 1 and 4 it can be shown that :

$\Delta=\left(\frac{R_{\mathrm{atm}}}{R_{p}}-1\right) \quad$ Equation 11

This does suggest that $\Delta$ is independent of the chosen isotopic standard, however similarly to the development above it can be shown, assuming that $\mathrm{R}_{\mathrm{atm}}$ is a constant, as it is often done in the literature, that :

$\mu_{\Delta}=\frac{1}{n} \sum\left(\frac{R_{\mathrm{atm}}}{R_{p_{i}}}-1\right)=\mathrm{R}_{\mathrm{atm}} \times \mu_{\frac{1}{R_{\mathrm{p}}}}-1$

where $\frac{\mu_{1}}{R_{p}}$ is the mean of the inverse of $R_{p}$, and

$\sigma_{\Delta}=\mathrm{R}_{\mathrm{atm}} \times \sigma_{\frac{1}{R_{p}}}$

where ${ }^{\sigma} \frac{1}{R_{p}}$ is the standard deviation of the inverse of $R_{p}$.

Therefore : 
$\mathrm{CV}_{\Delta}=\frac{\sigma_{\Delta}}{\mu_{\Delta}}=\frac{R_{\mathrm{atm}} \sigma_{\frac{1}{R_{p}}}}{R_{\mathrm{atm}} \mu_{\frac{1}{R_{p}}}-1}=\frac{\sigma_{\frac{1}{R_{p}}}}{\mu_{\frac{1}{R_{p}}}-\frac{1}{R_{\mathrm{atm}}}}$ Equation 12

Thus Equation 12, which has been plotted in Figure 2, shows that the CV estimated on a $\Delta$ value is dependent on the isotopic composition of atmospheric $\mathrm{CO}_{2}$.

\section{EXAMPLE DATA}

A data set of $\delta^{13} \mathrm{C}$ values measured on leaf material of trees was chosen as example data. The data is structured in 14 groups of 10 measurements each. Table 1 shows the descriptive statistics for the isotopic composition expressed on different scales. The isotopic ratio $\mathrm{R}$ were back-calculated from the $\delta^{13} \mathrm{C}$ data using the commonly used isotopic ratio for the Vienna PDB standard (VPDB $\mathrm{R}_{\mathrm{VPDB}}=$ $0.0111802^{[25]}$, based on the value for NBS-19 of $0.011202 \pm 0.000028^{[26]}$ ) and the following equation:

$\mathrm{R}=\delta^{13} C \times R_{\mathrm{VPDB}}+\mathrm{R}_{\mathrm{VPDB}}$

The back-calculated $\mathrm{R}$ values were then used to theoretically express isotopic composition on different scales. First, by using two different theoretical $\mathrm{R}_{\mathrm{ST}}$ and Equation 1: I) a $\mathrm{R}_{\mathrm{ST}}$ with an only slightly lower isotopic ratio by 0.000028 than VPDB, corresponding to the error of measurement of NBS-19 ${ }^{[26]}$ (" $\delta^{13} C-$-": $\left.R_{S T}=0.0111522\right)$; II) a $R_{S T}$ with a much lower isotopic ratio by 0.0014 , corresponding to the most depleted naturally occurring material ${ }^{[27]}\left("{ }^{13} \mathrm{C}-\right.$-" $\left.: \mathrm{R}_{\mathrm{ST}}=0.0097802\right)$. A similar reasoning was applied to the calculations of the relative isotope fraction $\Phi$, for $\Phi^{13} \mathrm{C}$ and $\Phi^{13} \mathrm{C}$ - using equation 3. Further, the isotopic composition was also expressed in atom fraction (equation 2) estimated from $\mathrm{R}$ as :

$\mathrm{AF}^{13} \mathrm{C}=\frac{R}{\mathrm{R}+1}$

A data set for nitrogen stable isotope $\left(\delta^{15} \mathrm{~N}\right)$ data was created by using the $\delta^{13} \mathrm{C}$ example data set and adding a constant value to shift the isotopic values into a range with a mean close to zero, as can be found for values in organic material and soil ${ }^{[28]}$. The resulting data set has the same standard deviation and range of values as the $\delta^{13} \mathrm{C}$ data set. Isotopic ratios $\left(\mathrm{R}^{15} \mathrm{~N}\right)$ were back-calculated using the isotopic ratio of atmospheric nitrogen $\left(0.0036765^{[5]}\right)$, which is the internationally accepted standard for $\delta^{15} \mathrm{~N}$.

Isotopic discrimination between atmospheric $\mathrm{CO}_{2}$ and organic plant material $(\Delta)$ was calculated according to Equation 4, using $-8 \%$, the generally used value for the $\delta^{13} \mathrm{C}_{\text {atm. }}$. Discrimination was also calculated using the $\delta$ notation that had been back-calculated with a different standard $\left(\delta^{13} \mathrm{C}--\right)$, where the corresponding $\delta^{13} \mathrm{C}_{\text {atm }}$ would be $+134 \%$ o $(\Delta--)$. Discrimination was also calculated using the standard $\delta$ scale, but different values for the isotopic composition of atmospheric $\mathrm{CO}_{2}\left(\delta^{13} \mathrm{C}_{\text {atm }}\right)$ :

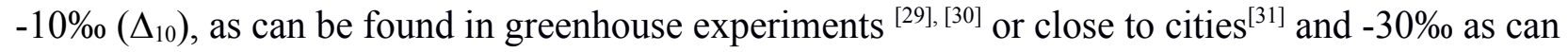
be found for bottled $\mathrm{CO}_{2}\left(\Delta_{30}\right)^{[32]}$.

These different isotopic scales, all representing the same data-set, were also used to run a standard analysis of variance for "groups" (Table 2).

Further, an analysis of variance components was done to estimate the genetic $\mathrm{CV}_{\mathrm{g}}$ as has been used by different authors ${ }^{[19-21]}$. For this, "Family" was used as a random grouping factor, which allowed to estimate a variance attributed to inter-family variation $\left(V_{\mathrm{fa}}\right)$ and a residual variance $\left(\mathrm{V}_{\mathrm{r}}\right)$. Narrow 
sense heritability $\left(\mathrm{h}^{2}\right)$ and $\mathrm{CV}_{\mathrm{g}}$ were then calculated as follows :

$$
\begin{aligned}
& h^{2}=\frac{4 V_{f}}{V_{f}+V_{r}} \\
& \mathrm{CV}_{g}=\frac{\sqrt{V_{f}}}{\mu}
\end{aligned}
$$

\section{RESULTS}

The theoretical considerations show that there is a direct, hyperbolic relationship between the CV and the $\mathrm{R}_{\mathrm{ST}}$ used to calculate the $\delta^{13} \mathrm{C}$ or the $\Phi^{13} \mathrm{C}$ scale (Figure 1). To illustrate this, a data set of $\delta^{13} \mathrm{C}$ values was used to express carbon isotopic composition using two isotopic ratios as standards that are different from VPDB, one reflecting its measurement error, the other one representing the most depleted naturally occurring material, and studying their effect on the resulting CV. When the same data-set is expressed in different isotopic scales, only $\mathrm{R}$ and atom fraction show a similar CV. Whereas the CVs of values expressed on the $\delta^{13} \mathrm{C}$ or $\Phi^{13} \mathrm{C}$ scales vary widely when calculated using different standards, however are similar for the same standard (Table 1). The slight difference in the $\mathrm{CV}$ between $\mathrm{R}$ and atom fraction is probably due to lack of precision of calculations using the very small values of $\mathrm{R}$. The $\mathrm{CV}$ calculated for $\Delta$ is different from the $\mathrm{CV}$ for $\mathrm{R}$, but it is independent of the isotopic standard used, as has already been shown by the theoretical considerations.

The $\mathrm{CV}$ estimated for the $\delta^{15} \mathrm{~N}$ data set is much higher compared to the $\delta^{13} \mathrm{C}$ data set with a similar range of values, the $\mathrm{CV}$ of the corresponding isotopic ratio data set is however similar to the one for carbon stable isotopes (Table 1).

The dependence of $\Delta$ on the isotopic composition of atmospheric $\mathrm{CO}_{2}\left(\delta^{13} \mathrm{C}_{\mathrm{atm}}\right)$ has similar consequences as the dependence of isotopic composition on the standard: a change in $\delta^{13} \mathrm{C}_{\text {atm }}$ changes the $\mathrm{CV}$ of the resulting discrimination values (Table 1; Figure 2).

Concerning an analysis of variance (Table 2), sums of squares (SS) are different between the different scales of isotopic composition, whereas the statistical result in terms of the F-test or the level of significance were strictly the same. Similarly concerning $\Delta$, different isotopic standards or different $\delta^{13} \mathrm{C}_{\text {atm }}$ did not affect the F-test or the significance level. Also for an analysis of variance components (Table 3), the choice of the isotopic standard or the $\delta^{13} \mathrm{C}_{\text {atm }}$ has no influence on the significance of the statistical model. Also when the estimated variances are used as ratios to calculate other parameters, e.g. here a genetic heritability, the different isotopic scales have no impact on the result, however they do influence the absolute values of variance and therefore also the absolute value of the genetic $\mathrm{CV}_{\mathrm{g}}$ in a very similar way as observed for means and standard deviations (Table 1).

\section{DISCUSSION}

The differential $\delta$ notation of isotopic abundances has been introduced to improve measurement precision and readability of small differences ${ }^{[33]}$. This is an advantage when isotopic measurements are compared among each other to study isotope effects or to trace elements e.g. in biological material. However, the result is that the delta value of isotopic composition is dependent on the standard used. For carbon stable isotopes, the theoretical relationship of $\delta^{13} \mathrm{C}$ of plant material with intrinsic water use efficiency $\left(\mathrm{W}_{\mathrm{i}}\right)^{[8]}$ gives it an apparent biological meaning, which results in comparisons of variability of $\delta^{13} \mathrm{C}$ with other biological traits using $\mathrm{CV}$. Visscher ${ }^{[34]}$ states that the $\mathrm{CV}$ should only be used if the mean has an intrinsic biological meaning. Additionally, the value "zero" should not be part of the range of values of a variable for which the CV is to be calculated, as then a risk exists that the mean is close to zero and therefore the CV infinite. This can be the case for isotopic abundances in the $\delta$ notation, as a value of or close to "zero" means that the sample is 
close to or has the same isotopic ratio as the standard. This is for example the case for natural abundances of ${ }^{15} \mathrm{~N}$ in plant material: since atmospheric nitrogen is the international isotopic standard ${ }^{[3]}, \delta^{15} \mathrm{~N}$ in studies of atmospheric nitrogen fixation can be close to zero, since there is very little fractionation during fixation ${ }^{[35]}$. This has also been shown quite clearly in the $\delta^{15} \mathrm{~N}$ data set used here, which has a significantly higher $\mathrm{CV}$ compared to the $\delta^{13} \mathrm{C}$ data set with the same SD and range of values.

The presented theoretical considerations as well as the example data set show clearly that a CV calculated for isotopic measurements expressed in the $\delta$ notation is still dependent on the standard used. This standard has been chosen arbitrarily and might be changed at any time. Actually, the original standard PDB is exhausted and has been replaced by a new scale (VPDB) ${ }^{[4]}$. Concerning the use of carbon isotope natural abundance as an estimator of intrinsic water use efficiency, the calculation of isotopic discrimination between $\delta^{13} \mathrm{C}_{\text {atm }}$ and $\delta^{13} \mathrm{C}_{\text {plant }}$ has been shown to be independent of the isotopic standard used for measurements. Isotopic discrimination could therefore theoretically be estimated based on absolute isotope ratios (e.g. equation 11) and therefore used to estimate a CV to compare to other traits. However, carbon isotopic discrimination is an indirect estimator for water use efficiency and thus the mean of a population of values has as such no direct biological meaning and a CV calculated on this basis should therefore not be used to compare to other traits ${ }^{[34]}$. Moreover, already relatively small variations in $\Delta$ could have a considerable indirect biological meaning, which had already been noted by Lauteri ${ }^{[21]}$, who detected a four times smaller CV for $\Delta$ (around 4\%) compared to growth traits (16-56\%), and questioned the comparability of the $\mathrm{CV}$ of these different traits. Further, the $\mathrm{CV}$ calculated from discrimination data is dependent on the $\delta^{13} \mathrm{C}$ value of atmospheric $\mathrm{CO}_{2}$ used for calculations. In most such studies, $\delta^{13} \mathrm{C}_{\text {atm }}$ is not measured precisely for each plant material harvested, but is assumed to be the same value for all plants in the experiment and considered to be equal to the generally accepted atmospheric value ${ }^{[18],[36-39]}$. Only in few studies it is actually measured ${ }^{[21],[40]}$. However, it is known that the $\delta^{13} \mathrm{C}_{\mathrm{atm}}$ is not a constant, but varies over time as fossil $\mathrm{CO}_{2}$ with $\delta^{13} \mathrm{C}$ values around $-27 \%$ has been injected into the atmosphere during the last 100 years ${ }^{[41]}$. It also shows seasonal and diurnal fluctuations within and above vegetation ${ }^{[42-44]}$. The value of $\delta^{13} \mathrm{C}_{\text {atm }}$ can also be very different for greenhouse and growth chamber experiments due to respiratory $\mathrm{CO}_{2}$ of plants and experimenters. Roussel ${ }^{[29]}$ have estimated, using the Zea maize method ${ }^{[45]}$, the $\delta^{13} \mathrm{C}_{\text {atm }}$ in a greenhouse as $-9.80 \pm 0.23 \%$. Bottled $\mathrm{CO}_{2}$, used in gas exchange experiments or for some phytotronic equipment, can have $\delta^{13} \mathrm{C}$ values of $-30 \%$ or lower ${ }^{[32]}$. This shows that the $\delta^{13} \mathrm{C}_{\text {atm }}$ could vary also between different experimentations and, as the $\mathrm{CV}$ is dependent on $\delta^{13} \mathrm{C}_{\mathrm{atm}}, \mathrm{CVs}$ estimated from different experimentations should not be compared without the assurance that the $\delta^{13} \mathrm{C}_{\text {atm }}$ had been measured. Similarly population genetic studies using dendrochronology and isotopic values from pre-industrial times would give underestimated CV compared to values from recent years. Overall, CV estimated from data-sets of isotopic measurements, as long as they have no intrinsic biological meaning, should not be compared to other traits or even to other isotopic measurements. For carbon isotopes as estimators of intrinsic water use efficiency $\left(\mathrm{W}_{\mathrm{i}}\right)$, the Farquhar model ${ }^{[8]}$ might be used to estimate values for $\mathrm{W}_{\mathrm{i}}$ from isotopic measurements, however, this would need the knowledge of all parameters of this model, which are specific to the species used and the experimental situation. Even though the above argument has been mainly developed for applications concerning carbon stable isotopes, it is valid for all other stable isotopes, when a coefficient of variation is used to compare variability with other traits, or in some cases even among isotopic experiments.

\section{ACKNOWLEDGEMENTS}

I'm especially indebted to Charlie Scrimegeour for the discussions we had on this subject and his help on an earlier and on this version of the manuscript. I also thank Nicolas Angeli, Delphine Derrien, Pierre Montpied and two anynomous reviewers for their helpful comments on the 
manuscript. The UMR EEF 1137 is supported by the French National Research Agency through the Laboratory of Excellence ARBRE (ANR-12- LABXARBRE-01). 


\section{REFERENCES}

[1] H. C. Urey. Oxygen Isotopes in Nature and in the Laboratory. Science. 1948, 108, 489.

[2] H. Craig. Isotopic standards for carbon and oxygen and correction factors for mass spectrometric analysis of carbon dioxide. Geochim. Cosmochim. Acta. 1957, 12, 133.

[3] J. M. Hayes. Fractionation, et al.: An introduction to isotopic measurements and terminology. Spectra. 1982, 8, 3.

[4] R. Gonfiantini. Advisory group meeting on stable isotope reference samples for genochemical and hydrological investigations. IAEA, Vienna, 1984.

[5] C. Slater, T. Preston, L. T. Weaver. Stable isotopes and the international system of units. Rapid Commun. Mass Spectrom. 2001, 15, 1270.

[6] T. B. Coplen. Guidelines and recommended terms for expression of stable-isotope-ratio and gas-ratio measurement results. Rapid Commun. Mass Spectrom. 2011, 25, 2538.

[7] T. N. Corso, J. T. Brenna. High-precision position-specific isotope analysis. Proc. Natl. Acad. Sci. 1997, 94, 1049.

[8] G. D. Farquhar, P. A. Richards. Isotopic composition of plant carbon correlates with water-use efficiency of wheat genotypes. Aust. J. Plant Physiol. 1984, 11, 539.

[9] A. G. Condon, R. A. Richards, G. J. Rebetzke, G. D. Farquhar. Improving intrinsic wateruse efficiency and crop yield. Crop Sci. 2002, 42, 122.

[10] A. M. Ismail, A. E. Hall. Carbon-isotope discrimination and gas-exchange of cowpea accessions and hybrids. Crop Sci. 1993, 33, 788.

[11] S. C. Gonzalez-Martinez, D. Huber, E. Ersoz, J. M. Davis, D. B. Neale. Association genetics in Pinus taeda L. II. Carbon isotope discrimination. Heredity (Edinb). 2008, 101, 19.

[12] R.R. Sokal, F.J. Rohlf. Biometry, The principles and practice of statistics in biological research. W.H. Freeman and Company, New York, 1995.

[13] B. V Bronk. Some inequalities for moments and coefficients of variation for a large class of probability functions. J. Appl. Probab. 1979, 16, 665.

[14] D. Houle. Comparing evolvability and variability of quantitative traits. Genetics. 1992, $130,195$.

[15] M. J. Aspinwall, J. S. King, S. E. McKeand, J. C. Domec. Leaf-level gas-exchange uniformity and photosynthetic capacity among loblolly pine (Pinus taeda L.) genotypes of contrasting inherent genetic variation. Tree Physiol. 2011, 31, 78. 
[16] L. Corcuera, E. Gil-Pelegrin, E. Notivol. Phenotypic plasticity in Pinus pinaster d13C: environment modulates genetic variation. Ann. For. Sci. 2010, 67, 812.

[17] B. Ehdaie, D. Barnhart, J.G. Waines. Genetic Analyses of Transpiration Efficiency, Carbon Isotope Discrimination, and Growth Characters in Bread Wheat, in Stable Isotopes and Plant Carbon-Water Relations, Academic Press San Diego, 1993, pp. 419-434.

[18] R. A. Jefferies. Physiological determinants of genotypic differences in carbon isotope discrimination in potato grown in well-watered conditions. Ann. Appl. Biol. 1995, 127, 585.

[19] A. A. Agrawal, A. C. Erwin, S. C. Cook. Natural selection on and predicted responses of ecophysiological traits of swamp milkeed (Asclepias incarnata). J. Ecol. 2008, 96, 536.

[20] M. K. Kanaga, R. J. Tyel, K. E. Mock, M. E. Pfrender. Quantiative-genetic variation in morphological and physiological traits within a quaking aspen (Populus tremuloides) populations). Can. J. For. Res. 2008, 38, 1690.

[21] M. Lauteri, A. Pliura, M. C. Monteverdi, E. Brugnoli, F. Villani, G. Eriksson. Genetic variation in carbon isotope discrimination in six European populations of Castanea sativa Mill. originating from contrasting localities. J. Evol. Biol. 2004, 17, 1286.

[22] G. Eriksson, A. Jonsson, M. Lauteri, A. Pliura. Genetic variation in drought response of Castanea sativa Mill. seedlings, in ISHS Acta Proceedings of the Third International Chestnut Congress, OCT 20-23, 2004, 2005, pp. 247-254.

[23] J.H. Zar. Biostatistical Analysis. Prentice Hall, 1999.

[24] O. Brendel, D. Le Thiec, C. Scotti-Saintagne, C. Bodenes, A. Kremer, J.-M. Guehl. Quantitative trait loci controlling water use efficiency and related traits in Quercus robur L. Trees Genet. Genomes. 2008, 4, 263.

[25] R. Werner, W. Brand. Referencing strategies and techniques in stable isotope ratio analysis. Rapid Commun. Mass Spectrom. 2001, 15, 501.

[26] Q. Zhang, W. Li. A calibrated measurement of the atomic weight of carbon. Chinese Sci. Bull. 1990, 35, 209.

[27] M. E. Wieser, T. B. Coplen. Atomic weights of the elements 2009 (IUPAC Technical Report). Pure Appl. Chem. 2011, 83, 359.

[28] L. L. Handley, C. M. Scrimgeour. Terrestrial Plant Ecology and 15N Natural Abundance: The Present Limits to Interpretation for Uncultivated Systems with Original Data from a Scottish Old Field. Adv. Ecol. Res. 1997, 27, 133.

[29] M. Roussel, D. Le Thiec, P. Montpied, N. Ningre, J.-M. Guehl, O. Brendel. Diversity of water use efficiency among Quercus robur genotypes: contribution of related leaf traits. Ann. 
For. Sci. 2009, 66, 408.

[30] J. S. Ebdon, K. L. Kopp. Relationships between Water Use Efficiency, Carbon Isotope Discrimination, and Turf Performance in Genotypes of Kentucky Bluegrass during Drought. Crop Sci. 2004, 44, 1754.

[31] L. Chmura, K. Rozanski, J. M. Necki, M. Zimnoch, T. Kuc, A. Korus. Atmospheric concentrations of carbon dioxide and its isotopic composition in southern Poland: comparison of high-altitude mountain site and a near-by urban environment. Biogeosciences Discuss. 2005, 2, 1849.

[32] T. T. N. Tu, P. Biron, K. Maseyk, P. Richard, B. Zeller, K. Quénéa, M. Alexis, G. Bardoux, V. Vaury, C. Girardin, V. Pouteau, D. Billiou, T. Bariac. Variability of 13C-labeling in plant leaves. Rapid Commun. Mass Spectrom. 2013, 27, 1961.

[33] W. A. Brand, T. B. Coplen. Stable Isotopes deltas: tiny, yet robust signatures in nature. Isotopes Environ. Health Stud. 2012, 48, 393.

[34] P. M. Visscher, W. G. Hill, N. R. Wray. Heritability in the genomics era - concepts and misconceptions. Nat. Rev. Genet. 2008, 9, 255.

[35] L. L. Handley, J. A. Raven. The use of natural abundance of nitrogen isotopes in plant physiology and ecology. Plant, Cell Environ. 1992, 15, 965.

[36] I. Aranda, R. Alia, U. Ortega, A. K. Dantas, J. Majada. Intra-specific variability in biomass partitioning and carbon isotopic discrimination under moderate drought stress in seedlings from four Pinus pinaster populations. Tree Genet. Genomes. 2010, 6, 169.

[37] M. Casasoli, D. Pot, C. Plomion, M. C. Monteverdi, T. Barreneche, M. Lauteri, F. Villani. Identification of QTLs affecting adaptive traits in Castanea sativa Mill. Plant Cell Environ. 2004, 27, 1088.

[38] K. J. Rice, D. R. Gordon, J. L. Hardison, J. M. Welker. Phenotypic variation in seedlings of akeystone tree species (Quercus douglasii) - The interactive effects of acorn source and competitive environment. Oecologia. 1993, 96, 537.

[39] R. C. Johnson, F. J. Muehlbauer, C. J. Simon. Genetic-Variation in Water-Use Efficiency and its relation to photosynthesis and productivity in lentil germplasm. Crop Sci. 1995, 35, 457.

[40] M. J. Pastorino, A. G. Aparicio, P. Marchelli, L. A. Gallo. Genetic variation in seedling water-use efficiency of Patagonian Cypress populations from contrasting precipitation regimes assessed through carbon isotope discrimination. For. Syst. 2012, 21, 189.

[41] R. Andres, T. Boden, G. Marland. Annual Fossil-Fuel CO2 Emissions: Global Stable Carbon Isotopic Signature. Oak Ridge, Tenn., U.S.A., 2012. 
[42] J. Lloyd, B. Kruijt, D. Y. Hollinger, J. Grace, R. J. Francey, S.-C. Wong, F. M. Kelliher, A. C. Miranda, G. D. Farquhar, J. H. C. Gash, N. N. Vygodskaya, I. R. Wright, H. S.

Miranda, E.-D. Schulze. Vegetation Effects on the Isotopic Composition af Atmospheric CO2 at Local and Regional Scales: Theoretical Aspects and a Comparison Between Rain Forest in Amazonia and a Boreal Forest in Siberia. Aust. J. Plant Physiol. 1996, 23, 371.

[43] M. Battle, M. L. Bender, P. P. Tans, J. W. C. White, J. T. Ellis, T. Conway, R. J. Francey. Global carbon sinks and their variability inferred from atmospheric O-2 and delta C-13.

Science (80-. ). 2000, 287, 2467.

[44] C. Allison, R. Francey. High precision stable isotope measurements of atmospheric trace gases, in Reference and intercomparison materials for stable isotopes of light elements, (Ed: IAEA ). Vienna, 1995, pp. 131-154.

[45] B. D. Marino, M. B. McElroy. Isotopic composition of atmospheric CO2 inferred from carbon in C4 plant cellulose. Nature. 1991, 349, 127. 
Table 1: Mean. standard deviation and coefficient of variation of the example data set $(\mathrm{N}=140)$ for isotopic compositions expressed in different scales: the original $\delta^{13} \mathrm{C}$ values, the back-calculated isotopic ratio $\mathrm{R}$ using VPDB (0.0111802), carbon isotopic compositions recalculated from $\mathrm{R}$ with an isotopic ratio of the standard that has been reduced slightly by $-0.000028\left(\delta^{13} \mathrm{C}-\right)$ or strongly by $-0.0014\left(\delta^{13} \mathrm{C}--\right)$, relative isotope fraction $\Phi^{13} \mathrm{C}$, relative isotope fraction with a slightly change standard as for $\delta^{13} \mathrm{C}\left(\Phi^{13} \mathrm{C}\right.$-), atom fraction $\mathrm{AF}^{13} \mathrm{C}$, carbon isotopic discrimination $(\Delta)$ calculated from the carbon isotopic composition $\left(\delta^{13} \mathrm{C}\right)$ and an assumed value of $\delta^{13} \mathrm{C}_{\text {atm }}$ for atmospheric $\mathrm{CO}_{2}$ of -8\%. D-- using $\delta^{13} \mathrm{C}$-- values (when using this standard the $\delta^{13} \mathrm{C}$-- value of atmospheric $\mathrm{CO}_{2}$ is $134 \%$ ), $\Delta 10$ and $\Delta 30$ using $-10 \%$ and $-30 \%$ or $\delta^{13} \mathrm{C}_{\text {atm }}$, respectively. Additionally a stable nitrogen isotopes $\left(\delta^{15} \mathrm{~N}\right)$ data set has been created with similar characteristics as the $\delta^{13} \mathrm{C}$ data set, and expressed on the delta scale as well as in absolute ratios $\left(\mathrm{R}^{15} \mathrm{~N}\right)$.

\begin{tabular}{llll}
\hline & Mean & Std.Dev. & Coef.Var. \% \\
\hline$\delta^{13} \mathrm{C}$ & $-26.23 \%$ & $0.62 \%$ & -2.36 \\
$\mathrm{R}^{13} \mathrm{C}$ & 0.010887 & 0.0000069 & 0.0635 \\
$\delta^{13} \mathrm{C}-$ & $-23.79 \% 0$ & $0.62 \% 0$ & -2.61 \\
$\delta^{13} \mathrm{C}--$ & $-113.16 \%$ & $0.71 \% 0$ & 0.63 \\
$\Phi^{13} \mathrm{C}$ & 25.95 & 0.61 & 2.36 \\
$\Phi^{13} \mathrm{C}-$ & 23.53 & 0.61 & 2.61 \\
$\mathrm{AF}{ }^{13} \mathrm{C}$ & 0.010770 & 0.000007 & 0.0628 \\
$\Delta$ & 18.72 & 0.65 & 3.46 \\
$\Delta--$ & 18.72 & 0.65 & 3.46 \\
$\Delta_{10}$ & 16.67 & 0.65 & 3.87 \\
$\Delta_{30}$ & -3.87 & 0.63 & -16.36 \\
\hline$\delta^{15} \mathrm{~N}$ & $0.37 \% 0$ & $0.62 \% 0$ & 168.15 \\
$\mathrm{R}^{15} \mathrm{~N}$ & 0.0036778 & 0.0000023 & 0.0618 \\
\hline
\end{tabular}


Table 2 Analysis of Variance of the example data set $(\mathrm{N}=140)$ for the same isotopic scales shown in Table 1, except for $\mathrm{R}$ and $\mathrm{AF}^{13} \mathrm{C}$, which were scaled by a factor of thousand. Shown is the complete analysis of variance with sum of squares (SS), degrees of freedom (df) and mean squares (MS) for the groups effect and the error term, respectively. Also shown is the result of the F-test and the level of significance $(* \mathrm{p}<0.0000005)$.

\begin{tabular}{|c|c|c|c|c|c|c|c|c|}
\hline & $\begin{array}{l}\text { SS } \\
\text { Effect }\end{array}$ & $\begin{array}{l}\text { df } \\
\text { Effect }\end{array}$ & $\begin{array}{l}\text { MS } \\
\text { Effect }\end{array}$ & $\begin{array}{l}\text { SS } \\
\text { Error }\end{array}$ & $\begin{array}{l}\text { df } \\
\text { Error }\end{array}$ & $\begin{array}{l}\text { MS } \\
\text { Error }\end{array}$ & $\mathrm{F}$ & $\mathrm{p}$ \\
\hline$\delta^{13} \mathrm{C}$ & 22.10 & 13 & 1.70 & 31.10 & 126 & 0.25 & 6.886 & $*$ \\
\hline $\mathrm{R} * 10^{3}$ & 0.0028 & 13 & 0.0002 & 0.0039 & 126 & 0.0000 & 6.886 & * \\
\hline$\delta^{13} \mathrm{C}-$ & 22.21 & 13 & 1.71 & 31.26 & 126 & 0.25 & 6.886 & $*$ \\
\hline$\delta^{13} \mathrm{C}--$ & 28.87 & 13 & 2.22 & 40.65 & 126 & 0.32 & 6.886 & $*$ \\
\hline$\Phi^{13} \mathrm{C}$ & 21.63 & 13 & 1.66 & 30.45 & 126 & 0.24 & 6.886 & $*$ \\
\hline$\Phi^{13} \mathrm{C}-$ & 21.74 & 13 & 1.66 & 30.45 & 126 & 0.24 & 6.886 & $*$ \\
\hline $\mathrm{AF}{ }^{13} \mathrm{C} * 10^{3}$ & 0.0026 & 13 & 0.0002 & 0.0037 & 126 & 0.00003 & 6.886 & $*$ \\
\hline$\Delta$ & 24.17 & 13 & 1.86 & 34.05 & 126 & 0.27 & 6.880 & * \\
\hline$\Delta--$ & 24.17 & 13 & 1.86 & 34.05 & 126 & 0.27 & 6.880 & $*$ \\
\hline$\Delta_{10}$ & 24.07 & 13 & 1.85 & 33.91 & 126 & 0.27 & 6.880 & $*$ \\
\hline$\Delta_{30}$ & 23.11 & 13 & 1.78 & 32.56 & 126 & 0.26 & 6.880 & $*$ \\
\hline
\end{tabular}


Table 3 Calculations of genetic variance from the example data set $(\mathrm{N}=140)$ for the same isotopic scales shown in Table 1, except for $\mathrm{R}$ and $A F^{13} \mathrm{C}$, which were scaled by a factor of thousand. Shown is the level of significance of the REML analysis $(\mathrm{p})$, the inter-family variance component $\left(\mathrm{V}_{\mathrm{fa}}\right)$, the residual intra family variance component $\left(\mathrm{V}_{\mathrm{r}}\right)$, the narrow sense heritability $\left(\mathrm{h}^{2}\right)$ and the genetic coefficient of variation $\left(\mathrm{CV}_{\mathrm{g}}\right)$.

\begin{tabular}{|c|c|c|c|c|c|c|}
\hline & $\mathrm{N}$ & REML $p$ & $\mathrm{~V}_{\mathrm{fa}}$ & $\mathrm{V}_{\mathrm{r}}$ & $\mathrm{h}^{2}$ & $\mathrm{CV}_{\mathrm{g}}$ \\
\hline$\delta^{13} \mathrm{C}$ & 10 & 0.029 & 0.15 & 0.25 & 1.48 & -0.0145 \\
\hline $\mathrm{R} * 10^{3}$ & 10 & 0.029 & $1.82 \mathrm{E}-05$ & $3.08 \mathrm{E}-05$ & 1.48 & 0.0004 \\
\hline$\delta^{13} \mathrm{C}-$ & 10 & 0.029 & 0.15 & 0.25 & 1.48 & -0.0161 \\
\hline$\delta^{13} \mathrm{C}--$ & 10 & 0.029 & 0.19 & 0.32 & 1.48 & 0.0038 \\
\hline$\Phi^{13} \mathrm{C}$ & 10 & 0.029 & 0.14 & 0.24 & 1.48 & 0.0145 \\
\hline$\Phi^{13} \mathrm{C}-$ & 10 & 0.029 & 0.14 & 0.24 & 1.48 & 0.0160 \\
\hline $\mathrm{AF}^{13} \mathrm{C} * 10^{3}$ & 10 & 0.029 & $1.74 \mathrm{E}-05$ & $2.95 \mathrm{E}-05$ & 1.48 & 0.0004 \\
\hline$\Delta$ & 10 & 0.030 & 0.16 & 0.27 & 1.48 & 0.0213 \\
\hline$\Delta--$ & 10 & 0.030 & 0.16 & 0.27 & 1.48 & 0.0213 \\
\hline$\Delta_{10}$ & 10 & 0.030 & 0.16 & 0.27 & 1.48 & 0.0239 \\
\hline$\Delta_{30}$ & 10 & 0.030 & 0.15 & 0.26 & 1.48 & -0.1007 \\
\hline
\end{tabular}


Figure headings:

Figure 1: Relationship between the isotopic ratio of the standard $\mathrm{R}_{\mathrm{ST}}$ and the $\mathrm{CV}$ [\%] calculated from Equation 10 using the example data set.

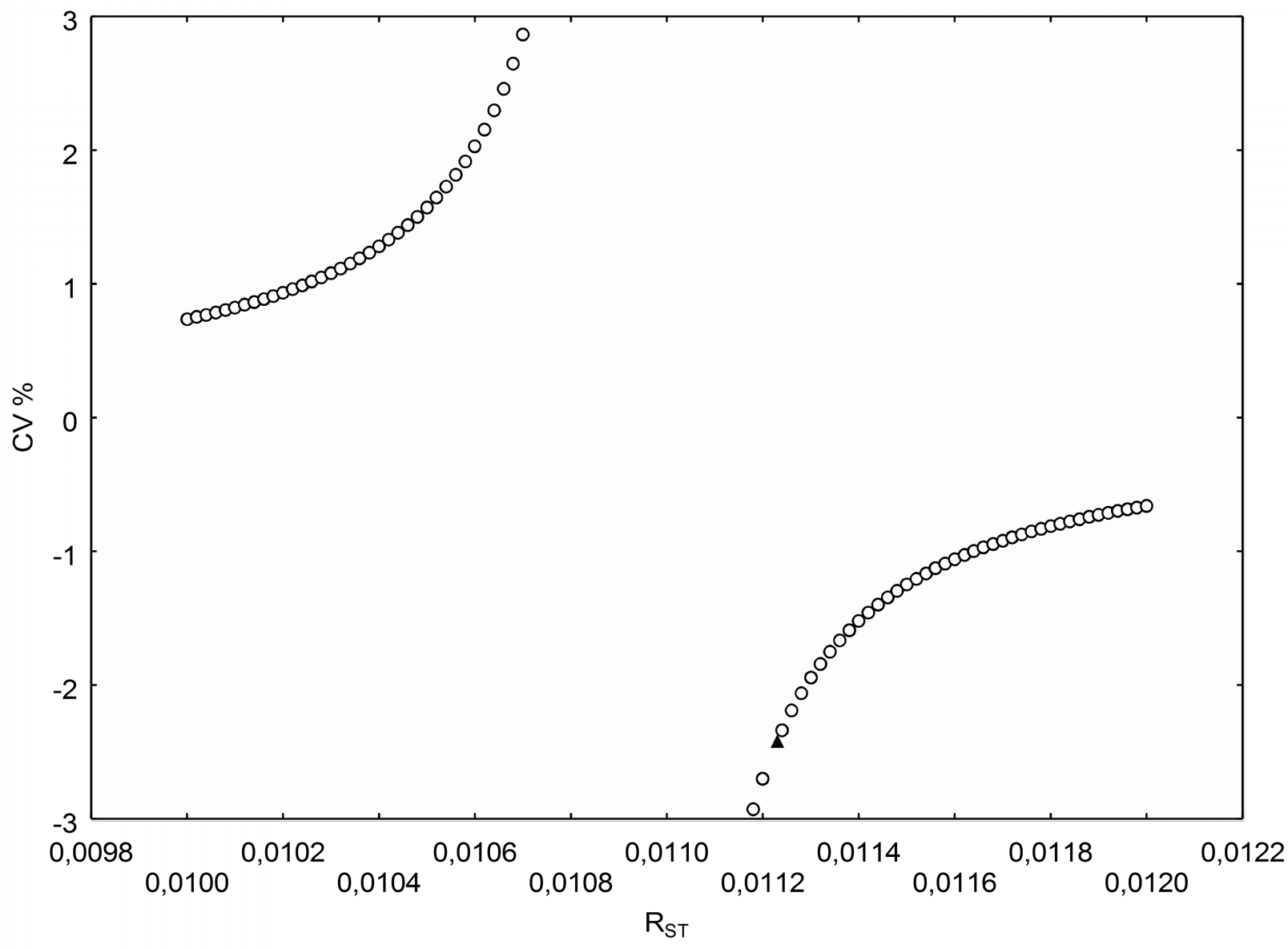


Figure 2: Dependence of CV from the value of $\delta^{13} \mathrm{C}_{\mathrm{atm}}$ using Equation 12. The black point is the usually assumed value of $-8 \%$, the grey box shows values actually observed, e.g. for greenhouse or growth cabinet experiments, whereas $\mathrm{CO}_{2}$ from gas bottles can have $\delta^{13} \mathrm{C}$ as low as $-30 \%$.

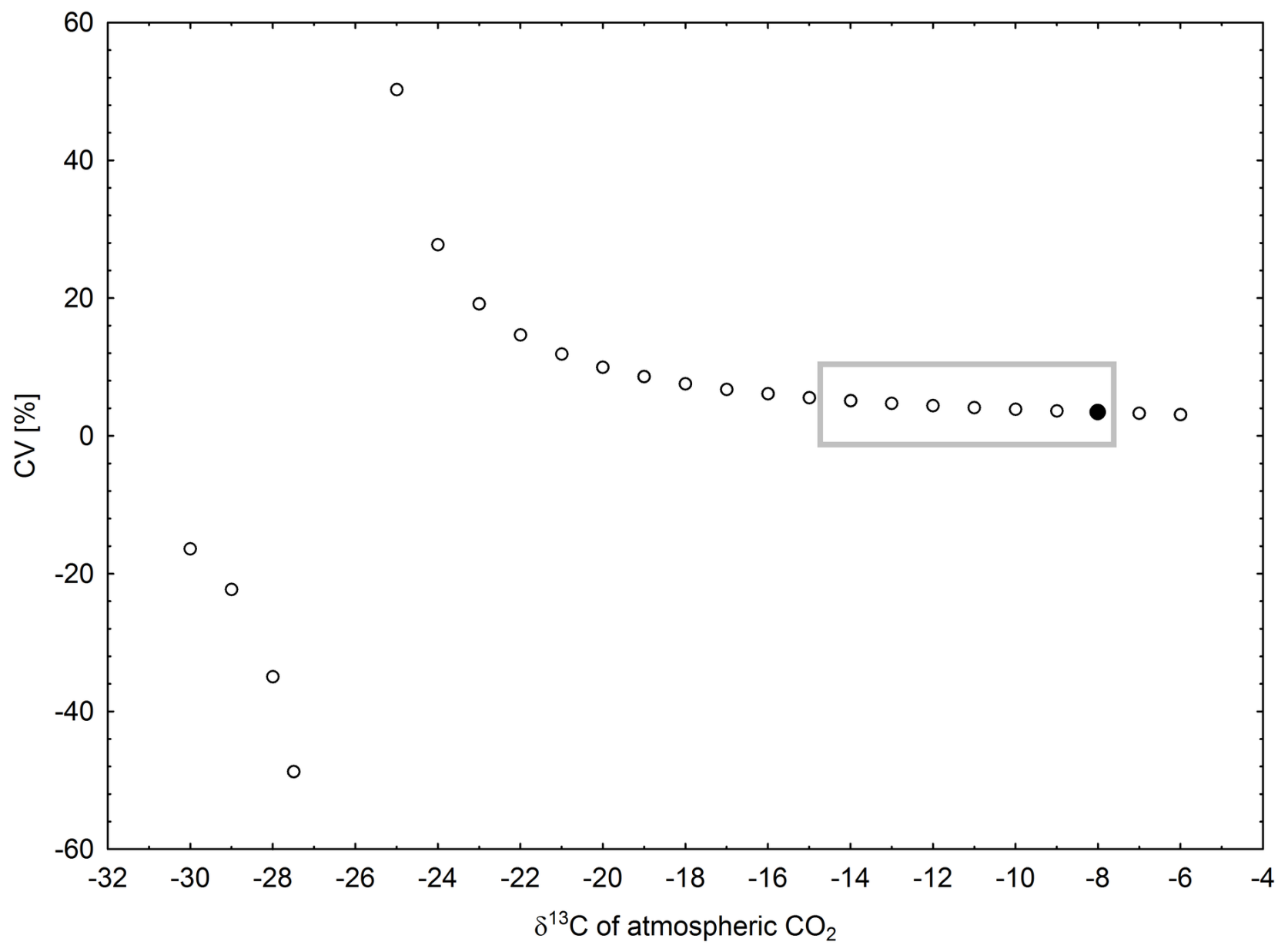

